\title{
The Research on the Guidance of Apple Futures Price Change to Spot Price
}

\author{
Hongmin Zhang*, Jun Guo
}

\author{
School of Finance, Harbin University of Commerce, Harbin, China \\ ${ }^{*}$ Corresponding author. Email: zhanghm0315@163.com
}

\begin{abstract}
On December 22, 2017, China's Zhengzhou Commodity Exchange officially announced the listing of Apple futures, which officially became China's first listed agricultural futures contract. The listing of Apple futures will help the country gradually realize the poverty alleviation policy and become an effective hedging financial tool to help the apple spot market, It has the function of price discovery and risk aversion. This paper selects the daily price data of Apple futures contract and Bohai commodity exchange from May 6, 2020 to November 30, 2020, and uses eviews10.0 software to study the relationship between Apple futures price and spot price. The empirical part shows that there is a certain co integration relationship between Apple futures price and apple spot price, and apple futures price guides apple spot price to a certain extent.
\end{abstract}

Keywords: Apple futures price, Cointegration test, Impulse response.

\section{INTRODUCTION}

There are many kinds of apple in China. Apple industry has been marketized to a higher degree in China. With the progress of planting technology and the improvement of weather resistance, apple production is increasing year by year, and apple price is also fluctuating frequently. Because of the lack of financial instruments to avoid the risk of apple price fluctuation, to some extent, the growers or enterprise organizations blindly hoard apple, which led to "low fruit damage farmers", and farmers and related enterprise organizations could not get the expected benefits. On December 22nd, 2017, Zhengzhou Commodity Futures Exchange officially announced the listing of Apple futures, which is not only the first fresh fruit futures variety to be listed in China, but also the first officially listed fresh fruit futures variety in the world. The emergence of Apple futures helps to form both open and transparent Apple prices in the market, and become derivatives tools for market participants to hedge and avoid price fluctuation risks, stabilize the production and operation activities of related industries and enterprises, and also ensure that farmers can effectively avoid the risk of price fluctuation and maintain stable income, which will be more effective for China In recent years, our family has been serving the poverty alleviation strategy and achieving the targeted poverty alleviation in the main apple production area. Before and after the Spring Festival in 2020, the sudden appearance of New Coronavirus epidemic not only had an impact on the national economic environment, but also had a great impact on Apple's transportation and marketing. Apple's market was bleak. In May of the same year, Apple was affected by freezing damage, and apple production was expected to decline, and futures prices began to fall from a high price of more than 9000 yuan per ton. After Apple was picked in October, futures prices rose again. The interaction between Apple futures market and spot market makes the price changing constantly. In recent three years, the volume of trading has been increasing. The study of the relationship between Apple futures price and apple spot price is helpful to the management of risk and maintain the stability of Apple futures market and spot market.

\section{LITERATURE REVIEW}

(Ma Di, Zhang Huan, he Peidong, Lu Shounan, Kong JINZI, Wang Xu, 2019) using the price data of Qixia Red Fuji apple in Yantai, Shandong Province and the apple futures data to make a linear analysis of the two, it is concluded that the apple futures price can predict the apple spot price, guide the change of spot price, and has a significant impact. 
(Wang Yunyuan, 2019) co integration test, Granger causality test and error correction model were conducted by using the data of Apple futures price in Zhengzhou Commodity Futures Exchange and Fuji apple spot price in Shaanxi. The results show that there is a significant positive correlation between the futures and spot price.

(Gao Yang, Fang Xinyue, Luo Xiao 2020) using the apple futures price and the apple spot data price of Henan Shangqiu, Gansu Jingning, Henan Lingbao to carry out Granger causality test, impulse response analysis and CS model, it is concluded that the efficiency of Apple futures price discovery is not high, and it can not process the market information quickly. The guidance of apple spot is weak.

(Wang Xiaolin, Shi Ruo, 2019) using China Fuji apple price index as the spot price and apple futures price of Zhengzhou Commodity Futures Exchange for Granger causality test and impulse response analysis, it is concluded that the price discovery effect of Apple futures contract is different between different months, and there is a long-term equilibrium relationship between Apple futures price and apple spot price. The transmission efficiency of futures market is low.

\section{SOURCE AND SELECTION OF DATA}

This paper selects the daily apple futures and apple spot data from May 6, 2020 to November 30, 2020. The daily apple futures price data comes from the wind database, the daily apple main futures data (unit: yuan / ton), and the daily apple spot price data comes from the wind database Bohai commodity exchange apple daily price (unit: yuan / kg). First, the data are processed in the same unit: yuan / ton. Take logarithm processing for the above Apple futures data and apple spot data to prevent data from heteroscedasticity. Using Eviews 10.0 software for empirical analysis. The futures price of apple is represented by LNX, and the spot price of apple is represented by LNY. For the first-order difference data, the apple futures price after the first-order difference is expressed by dlnx, and the apple spot price after the first-order difference is expressed by dlny.

\section{EMPIRICAL ANALYSIS}

\subsection{Unit Root Test}

Whether the data is stable or not is very important to the research results. If the variable sequence is nonstationary, it will lead to the problem of pseudo regression. In order to solve this problem, the following analysis chooses to establish the VAR model and carry out ADF test on it. Table 1 below shows the test results.
Table 1. ADF test

\begin{tabular}{|c|c|c|c|c|c|}
\hline $\begin{array}{c}\text { Vari } \\
\text { able }\end{array}$ & $\begin{array}{c}\mathrm{T} \\
\text { statisti } \\
\mathrm{C}\end{array}$ & $\begin{array}{c}1 \% \\
\text { critical } \\
\text { value }\end{array}$ & $\begin{array}{c}5 \% \\
\text { critical } \\
\text { value }\end{array}$ & $\begin{array}{c}\mathrm{P} \\
\text { value }\end{array}$ & $\begin{array}{c}\text { Concl } \\
\text { usion }\end{array}$ \\
\hline Lnx & - & - & - & 0.157 & Unsta \\
& $\begin{array}{c}1.3712 \\
85\end{array}$ & $\begin{array}{c}2.58158 \\
4\end{array}$ & $\begin{array}{c}1.94312 \\
3\end{array}$ & 6 & ble \\
\hline $\begin{array}{c}\mathrm{D}(\mathrm{L} \\
\mathrm{nx})\end{array}$ & $\begin{array}{c}11.461 \\
55\end{array}$ & $\begin{array}{c}2.58170 \\
5\end{array}$ & $\begin{array}{c}1.94314 \\
0\end{array}$ & $\begin{array}{c}0.000 \\
0\end{array}$ & Stable \\
\hline Lny & - & - & - & 0.130 & \\
& $\begin{array}{c}1.4755 \\
00\end{array}$ & $\begin{array}{c}2.58195 \\
1\end{array}$ & $\begin{array}{c}1.94317 \\
5\end{array}$ & 6 & ble \\
\hline $\begin{array}{c}\mathrm{D}(\mathrm{L} \\
\mathrm{ny})\end{array}$ & - & - & - & 0.006 & \\
& 3.760 & 2.58195 & 1.94317 & 3 & Stable \\
\hline
\end{tabular}

As can be seen from table 1 above, apple futures price data and apple spot price data have not passed the ADF test, and the variables are non-stationary. The tstatistics of the data after the first-order difference are less than the critical value of significance level of $1 \%$, and the two groups of data are stationary series. The two groups of time series data are first-order single integration series, on this basis, the co integration test will continue.

\subsection{Johansen Cointegration Test}

The purpose of Johansen cointegration test is to prevent the occurrence of pseudo regression between variables. When there is a real long-term equilibrium relationship in the real economic phenomenon, under normal circumstances, there is a cointegration relationship between the variables corresponding to the existing data obtained after statistical test. On the contrary, it is not. The results of Johansen co integration test are shown in Table 2 and Table 3. For the data of Apple futures and apple spot after the first-order differential processing, the Johansen co integration test takes the critical value of $5 \%$ significance level as the standard, and the characteristic root trace is 58.78626 , which is greater than the standard value under the $5 \%$ level. The original hypothesis is rejected, and the conclusion that there is a co integration relationship between Apple futures price and apple spot price is obtained. At the same time, the result of the maximum eigenvalue is 49.22277, which is greater than the standard value at the level of $5 \%$, and the original hypothesis is rejected. Through further testing, we can get the conclusion that the hypothesis that there is at most one co integration relationship is rejected. Therefore, it can be seen that there is a co integration relationship between Apple's futures price and spot price, and the relationship between them is balanced. 
Table 2. Unrestricted cointegration rank test (trace)

\begin{tabular}{|c|l|l|l|l|}
\hline $\begin{array}{l}\text { Hypothesize } \\
\text { d No. of } \\
\text { CE(s) }\end{array}$ & $\begin{array}{l}\text { Elgenvalu } \\
\text { e }\end{array}$ & $\begin{array}{l}\text { Trace } \\
\text { Statistic }\end{array}$ & $\begin{array}{l}0.05 \\
\text { Critical } \\
\text { Value }\end{array}$ & $\begin{array}{l}\text { Prob.* } \\
*\end{array}$ \\
\hline None & 0.301828 & 58.78626 & 15.49471 & 0.0000 \\
\hline At most $1 *$ & 0.067426 & 9.563496 & 3.841466 & 0.0020 \\
\hline
\end{tabular}

Table 3. Unrestricted cointegration rank test (maximum eigenvalue)

\begin{tabular}{|l|l|l|l|l|}
\hline $\begin{array}{l}\text { Hypothesize } \\
\text { d No. of } \\
\text { CE(s) }\end{array}$ & Eigenvalu & $\begin{array}{l}\text { Max- } \\
\text { Eigen } \\
\text { Statistic }\end{array}$ & $\begin{array}{l}0.05 \\
\text { Critical } \\
\text { Value }\end{array}$ & $\begin{array}{l}\text { Prob.* } \\
*\end{array}$ \\
\hline None * & 0.301828 & $\begin{array}{c}49.2227 \\
7\end{array}$ & $\begin{array}{c}14.2646 \\
0\end{array}$ & 0.0000 \\
\hline At most $1 *$ & 0.067426 & $\begin{array}{c}9.56349 \\
6\end{array}$ & $\begin{array}{c}3.84146 \\
6\end{array}$ & 0.0020 \\
\hline
\end{tabular}

\subsection{Granger Causality Test}

Granger causality test is to test whether the lag value of a variable can predict the information of the explained variable. From the data in Table 4, we can draw a conclusion: at the 5\% significance level, reject the original hypothesis that LNX is the Granger cause of LNY, and accept the original hypothesis that LNY is not the Granger cause of LNX. It is concluded that Apple futures price is the Granger cause of apple spot price. In other words, the historical information of Apple futures can predict the current information of apple spot.

Table 4. Granger causality test

\begin{tabular}{|c|c|c|c|}
\hline Null Hypothesis: & Obs & F-Statistic & Prob. \\
\hline $\begin{array}{c}\text { LNY does not } \\
\text { Granger Cause LNX }\end{array}$ & 138 & 0.74742 & 0.5257 \\
\hline $\begin{array}{c}\text { LNX does not } \\
\text { Granger Cause LNY }\end{array}$ & & 2.73483 & 0.0463 \\
\hline
\end{tabular}

\subsection{VAR Model}

In order to carry out impulse response analysis and variance decomposition analysis on the data, it is necessary to establish a stable VAR model first. To establish a stable VAR model, it is necessary to determine the lag order. Combined with the following table for analysis, the lag order of the model is 3 . See Table 5.

Table 5. Lag test

\begin{tabular}{|c|c|c|c|c|c|c|}
\hline Lag & LogL & LR & FPE & AIC & SC & HQ \\
\hline 0 & $\begin{array}{c}636.7 \\
334\end{array}$ & NA & $\begin{array}{c}2.28 \mathrm{e}- \\
07\end{array}$ & $\begin{array}{c}9.617173 \\
1\end{array}$ & -9.573494 & $\begin{array}{c}- \\
9.599424\end{array}$ \\
\hline 1 & $\begin{array}{c}654.4 \\
349\end{array}$ & $\begin{array}{c}34.5983 \\
8\end{array}$ & $\begin{array}{c}1.85 \mathrm{e}- \\
07\end{array}$ & $\begin{array}{c}- \\
9.824771\end{array}$ & $-9.693735^{*}$ & $\begin{array}{c}- \\
9.771524\end{array}$ \\
\hline 2 & $\begin{array}{c}663.3 \\
503\end{array}$ & $\begin{array}{c}17.1553 \\
3\end{array}$ & $\begin{array}{c}1.72 \mathrm{e}- \\
07\end{array}$ & $\begin{array}{c}9.899247 \\
-\end{array}$ & -9.680853 & $\begin{array}{c}9.810501 \\
*\end{array}$ \\
\hline 3 & $\begin{array}{c}669.1 \\
172\end{array}$ & $\begin{array}{c}10.9222 \\
2^{*}\end{array}$ & $\begin{array}{c}1.68 \mathrm{e}- \\
07^{*}\end{array}$ & $\begin{array}{c}9.926018 \\
*\end{array}$ & -9.620267 & - \\
\hline 4 & $\begin{array}{c}669.7 \\
477\end{array}$ & $\begin{array}{c}1.17494 \\
3\end{array}$ & $\begin{array}{c}1.76 \mathrm{e}- \\
07\end{array}$ & $\begin{array}{c}- \\
9.874965\end{array}$ & -9.481855 & $\begin{array}{c}- \\
9.715223\end{array}$ \\
\hline
\end{tabular}

After the lag period of VAR model is determined, the stability of VAR model needs to be tested. As shown in Figure 1 below, it is obvious that the unit root of VAR model falls in the unit circle, which indicates that the VAR model has passed the stability test. So the VAR model is stable.

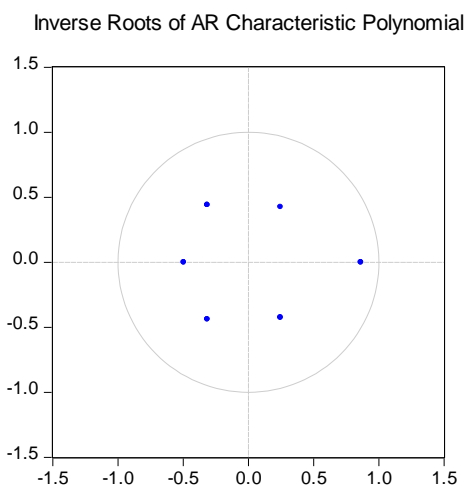

Figure 1 Unit root test

\subsection{Impulse Response Analysis and Variance Decomposition}

The dynamic change path of time series can be expressed by impulse response function (IRF). It can clearly show the dynamic influence of each variable. Impulse response analysis and variance decomposition are carried out using the apple futures price data and apple spot price data after the first-order difference. The results are shown in Table 2 . The abscissa in the figure represents the number of impact periods, and a total of 10 periods are selected for observation. The ordinate represents the rate of change, which refers to the price response to the impact of a unit standard deviation. As can be seen from the figure, Apple's spot price shows a downward trend from phase 1 to phase 2 after being impacted by the spot price, rises slowly from phase 2 to phase 4 , then declines slowly after phase 4 , and tends to be stable with the increase of phases; Apple's spot price rises slowly from phase 2 to phase 4 after being impacted by Apple's futures price, and then shows a downward trend, and finally tends to be stable; Apple's spot price is impacted by the futures price After the impact of apple spot price on the spot price, the spot price of the first to the second period dropped suddenly, reached the lowest point of negative value in the fourth period, and began to rise after the fourth period, tending to be stable. It can be seen that Apple's futures price and spot price have great influence on their futures market and spot market prices, and have a negative effect. The influence of Apple's futures price on spot market price is slightly greater than that of spot market price on futures market price, which indicates that futures price plays a role in price discovery to a certain extent, And futures prices and spot prices are more affected by their own price market. 

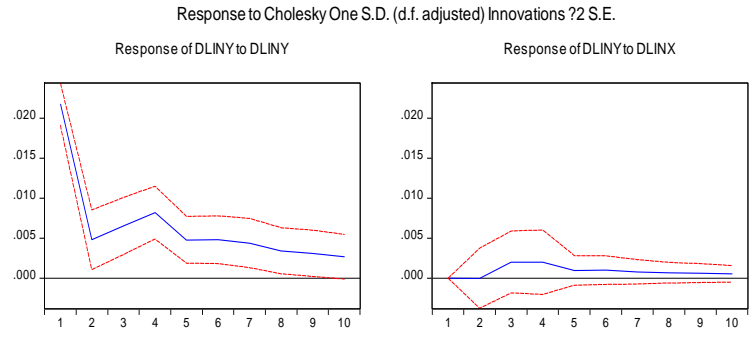

Response ofDLINX to DLINY


Figure 2 Variance decomposition

\section{CONCLUSION}

Conclusion: according to the empirical part of this paper, we can see that: firstly, there is a co integration relationship between Apple futures price and spot price in China, and apple futures price can guide apple spot price to a certain extent. Secondly, Apple's futures price and spot price have a great impact on their respective markets, and the impulse response chart shows that they have a negative effect on their own markets. Finally, for the empirical part of the paper, the apple spot price data is directly retrieved from the database, and the quality level of apple is not selected for the purpose of screening data. This year, COVID-19's national economic situation is affected. The conclusion in the empirical part can explain the effect of futures price on spot price discovery to a certain extent. With the continuous improvement and development of the futures market, apple futures will play a better role in price discovery.

Suggestions: 1. Actively promote the "insurance + futures" model: apple is affected by natural weather, blind hoarding by individual farmers and enterprises, and its price fluctuates frequently. Apple futures is a new variety of fresh agricultural products futures market, and China's fresh futures market has further development space. The introduction of Apple futures can promote the country's financial poverty alleviation. The application of "insurance + futures" mode for insurance companies and futures companies can help insured farmers reduce the risk of apple spot price fluctuation and avoid the risk of Apple futures price fluctuation, so as to ensure the healthy development of apple market. Therefore, we need to actively guide farmers and social organizations to participate, and learn about futures knowledge and trading rules, and improve the risk prevention awareness of futures.

2. Regulatory authorities should strengthen supervision and improve corresponding laws and regulations: for Apple futures with short listing period, relevant regulatory authorities need to strengthen supervision and improve the legal system of futures market, so as to promote the standardized development of futures market, protect the legitimate rights and interests of investors and consumers, prevent speculators from maliciously manipulating futures market, so as to protect the market To realize the coordinated operation of futures market and spot market.

3. Innovating financial products and promoting the convenient development of derivatives trading: with the gradual development of China's economy, financial instruments are constantly innovating and upgrading, and the types of financial products are increasing, which provides more opportunities for market investors to participate and helps to meet the needs of investors. Hedging or risk aversion by futures has become the choice of many investors. In the era of rapid development of the Internet, the use of the Internet as a convenient channel to promote the innovation and progress of financial derivatives, to inject power into the development of the futures market.

\section{REFERENCES}

[1] Ma Di, Zhang Huan, he Peidong, Lu Shounan, Kong JINZI, Wang Xu. Research on the influence of Apple futures price on apple price [J]. Tax payment, 2019,13 (34): $186+189$

[2] Wang Yunuan. An Empirical Study on the relationship between Apple futures price and spot price [J]. Shang Xun, 2019 (18): 113-114

[3] Wang Xiaolin, Shi Ruo. Research on the relationship between Apple futures price and spot price in China [J]. Economic circles, 2019 (06): 2939

[4] Gao Yang, Fang Xinyue, Luo Xiao. An Empirical Study on the price discovery function of fresh futures -- Taking egg futures and apple futures as examples [J]. China Securities Futures, 2020 (01): $32-40$

[5] Wei Mingying, Liao Yijing. Empirical analysis on price discovery function of China's egg futures market based on VAR model [J]. Journal of Liaoning University of Technology (SOCIAL SCIENCE EDITION), 2020,22 (05): 28-31

[6] Lu Ting, Huang wanmeng, Yin Yaoqing, Pei Yu. Research on financial poverty alleviation of fresh agricultural products in China -- Taking "insurance + futures" of eggs and apples as an example [J]. Rural science and technology, 2019 (17): 26-28 